\title{
Redesign Road Project Using Critical Chain Project Management Method and Crashing Method
}

\section{Perencanaan Ulang Proyek Jalan Menggunakan Metode Critical Chain Project Management Dan Metode Crashing}

\author{
Arif Budi Sulistyo", Ilpan', Afni Khadijah" \\ ${ }^{1}$ Program Studi Teknik Industri, Fakultas Teknik, Universitas Banten Jaya \\ Jl. Ciwaru Raya No.73, Cipare, Kec. Serang, Kota Serang, Banten \\ email : arif.b.sulistyo@gmail.com \\ doi: https://doi.org/10.31315/opsi.v14i2.5651
}

Received: 22 nd October 2021; Revised: $4^{\text {th }}$ December 2021; Accepted: $6^{\text {th }}$ December 2021;

Available online: 21 ${ }^{\text {st }}$ December 2021; Published regularly: December 2021

\begin{abstract}
Construction of the Provincial road project from Parigi to Sukamanah is carried out by PT. Jaya Madiri Konsulindo as consultant and PT. Karya Tunas Mandiri Persada as contractor. The problem of the construction project is implementation duration does not match to previous planning which results delay in completion time. It is necessary to re-plan the project in order to get either optimal time or cost. The purpose of this research is to find out the critical work path using critical chain project managemet method by utilizing microsoft project software and optimization of project time and cost using crashing method with alterative increase of working hours (overtime) and addition of labor. The research' scope is limited on labor cost only. Based on the results of the study obtained that initial labor wage cost is IDR 585,025,000.00 with a working duration of 154 days, and results of the alterative crashing method is lower with labor wage cost IDR 576,750,000.00. It could save cost about IDR 8,275,000.00 with duration of work 150 days or earlier 4 days from the initial duration.
\end{abstract}

Keywords: Critical Chain Project Management; Crashing; Critical Job Path; Scheduling

\begin{abstract}
ABSTRAK
Pembangunan proyek jalan Provinsi ruas jalan Parigi sampai Sukamanah dilaksanakan oleh PT. Jaya Mandiri Konsulindo sebagai konsultan dan PT. Karya Tunas Mandiri Persada sebagai kontraktor. Permasalahan yang terjadi pada pembangunan proyek jalan tersebut adalah pelaksanaan proyek yang tidak sesuai dengan waktu perencanaan sehingga mengakibatkan proyek mengalami keterlambatan waktu penyelesaian. Untuk itu diperlukan perencanaan proyek agar menghasilkan waktu dan biaya yang optimal. Tujuan penelitian ini adalah untuk megetahui jalur pekerjaan kritis menggunakan metode critical chain project managemet dengan aplikasi microsoft project dan optimalisasi waktu dan biaya proyek meggunakan metode crashing dengan alternatif penambahan jam kerja (lembur) dan penambahan tenaga kerja. Penelitian ini hanya membahas biaya tenaga kerja saja. Berdasarkan hasil penelitian didapatkan bahwa biaya upah tenaga kerja awal sebesar Rp. 585,025,000.00 dengan durasi waktu kerja 154 hari, sedangkan hasil yang didapatkan dari crashing dengan melakukan penambahan tenaga kerja adalah biaya upah tenaga kerja sebesar Rp. 576,750,000.00 atau dapat menghemat biaya sebesar Rp. 8,275,000.00, dan waktu proyek 150 hari atau 4 hari lebih cepat.
\end{abstract}

Kata Kunci: Critical Chain Project Management; Crashing; Jalur Pekerjaan Kritis; Penjadwalan

\section{LATAR BELAKANG}

Permasalahan proyek konstruksi jalan yang sering ditemui adalah pada tahap pelaksanaan, dimana sering terjadi perubahan yang mengakibatkan keterlambatan penyelesaian proyek. Hal ini juga terjadi saat pembangunan proyek jalan provinsi ruas jalan Parigi sampai Sukamanah yang dilaksanakan oleh PT. Jaya MandiriKonsulindo sebagai konsultan dan PT. Karya Tunas Mandiri Persada sebagai kontraktor. Manajemen proyek merupakan suatu proses dimana individu sebagai bagian 
dari organisasi yang berpartisipasi dalam pemeliharaan, pengembangan, pengendalian dan menjalankan program yang selaras dengan tujuan yang ditetapkan dan berlangsung terus menerus seiring dengan berjalannya waktu (Setiawan et al., 2017). Faktor potensial yang dapat mempengaruhi keterlambatan proyek yaitu tenaga kerja, pengiriman dan kondisi bahan baku pembangunan jalan, peralatan yang digunakan, karakteristik tempat, dan intensitas curah hujan tinggi yang mengganggu pelaksanaan proyek. Hal ini juga terjadi pada proyekpembangunan jalan provinsi ruas jalan Parigi dan Sukamanah pada tahun 2019, sehingga waktu penyelesaian proyek tidak sesuai dengan waktu perencanaan awal proyek tersebut. Oleh sebab itu, proyek tidak berjalan dengan lancar dan mengakibatkan penambahan waktu yang melebihi dari perencanaan awal, sehingga ada proyek yang tertunda atau tidak dapat di lanjutkan. Dalam hal ini dibutuhkan perencanaan penjadwalan proyek yang lebih baik sehingga proyek dapat berjalan sesuai dengan rencana yang telah disusun dan tidak menyebabkan penambahan waktu proyek atau mengakibatkan proyek tertunda. Peneliti melakukan studi kasus pada perencanaan ulang proyek pembangunan jalan provinsi ruas jalan Parigi sampai Sukamanah Kecamatan Serang, Banten dengan sistem perencanaan pembangunan jalan menggunakan metode critical chain project management (microsoft project) dan metode Crashing dengan alternatif penambahan tenaga kerja dan alternatif penambahan jam kerja.

Hasil penelitian yang dilakukan diharapkan bisa menjadi rujukan bagi konsultan dalam merencanakan proyek, guna menghindari keterlambatan waktu proyek dan meminimalkan biaya proyek. Penjadwalan proyek merupakan salah satu elemen hasil perencanaan, yang dapat memberikan informasi tentang jadwal rencana dan kemajuan proyek dalam hal kinerja sumber daya berupa biaya, tenaga kerja, peralatan dan material serta rencana durasi proyek dan progres waktu penyelesaian proyek (Olivia \& Puspasari, 2019).

Hasil penelitian yang dilakukan diharapkan bisa menjadi rujukan bagi konsultan dalam merencanakan proyek, guna menghindari keterlambatan waktu proyek dan meminimalkan biaya proyek. Pada metode Critical Chain Project Management ini penambahan waktu aman (safety time) yang biasanya diletakkan pada setiap aktivitas jalur kritis akan dihilangkan dan digantikan dengan waktu penyangga (buffertime) yang diletakkan diakhir critical chain sebagai cadangan waktu pada keseluruhan proyek. Apabila hal-hal yang tidak diinginkan terjadi saat pelaksanaan proyek, maka dapat diantisipasi dengan adanya waktu penyangga (buffer time) sehingga terhindar dari keterlambatan waktu proyek yang telah direncanakan. Metode crashing yang digunakan dapat memunculkan alternatif dalam rangka menghindari keterlambatan waktu proyek dengan cara menambah jam kerja atau penambahan tenaga kerja pada proyek.

Critical Chain project Management (CCPM) mengambil dasar metode dan algoritma dari TOC (Theory Of Constraint). Ide dari CCPM dikembangkan dan diperkenalkan oleh Dr. Elihayu M Goldratt pada tahun 1997 dalam bukunya yang berjudul Critical Chain. CCPM atau dikenaljuga sebagai metode rantai kritis adalah metode perencanaan dan pengolahan proyek yang menekankan pada sumber daya yang diperlukan dalam rangka melakukan tugas proyek (Sinaga \& Husin, 2021). Tujuan dari penggunaan CCPM dalam menyelesaikan proyek adalah untuk meningkatkan tingkat throughput atau tingkat penyelesaian proyek (Ningrum et al., 2017). Bidang tantangan lain bagi manajer proyek yang menerapkan metode CCPM adalah perencanaan sumber daya. Saat merencanakan sumber daya di lingkungan multi-proyek, metode rantai kritis merekomendasikan untuk mengerjakan proyek awal di sekitar sumber daya utama. Ini digunakan untuk memastikan aliran dan menghindari terlalu banyak proyek terbuka yang mengakibatkan multitasking berlebihan dan melewatkan tenggat waktu (Araszkiewicz, 2017).

Upaya yang dapat dilakukan untuk mempercepat durasi waktu suatu proyek disebut crashing. Proses crashing dilakukan dengan cara mempercepat durasi suatupekerjaan pada proyek yang akan berpengaruh terhadap waktu penyelesaian proyek. Crashing adalah suatu proses yang disengaja, sistematis, dan analitik denganupaya melakukan pengujian dari semua kegiatan dalam suatu proyek yang dipusatkan pada kegiatan yang berada pada jalur kritis (Olivia \& Puspasari, 2019). Analisis perhitungan perceptan biaya proyek konstruksi 
dengan menggunakan metode Time Cost Trade Off, sehingga dengan metode tersebut suatu kontraktor dapat melihat waktu dan biaya yang lebih efisien dalam menyelesaikan suatu konstruksi (Tegar et al., 2020). Seperti penelitian pada Proyek Pembangunan Hotel Grand Keisha, Yogyakarta dihasilkan dengan penambahan jam kerja diperoleh pengurangan biaya sebesar Rp.1.012.856.772,54 dari biaya normal Rp.90.620.898.879,84 menjadi Rp.89.608.042.107,30 dengan durasi 392 hari, bila dilakukan shift kerja terjadi pengurangan biaya Rp.1.240.492.176,44 menjadi Rp.89.380.406.703,40 dengan durasi 382 hari (Giri et al., 2017). Juga studi kasus pada peningkatan jalan Pelantaran-ParenggeanTumbang Sangai, durasi proyek bisa dipercepat 10 hari menjadi 590 hari, efisiensi waktu sebesar $1,67 \%$ dan menghemat biaya proyek $\mathrm{Rp}$ 500.023.306,- menjadi Rp 72.374.976.694, dengan efisiensi biaya $0,69 \%$ (Olivia \& Puspasari, 2019). Faktor-faktor keterlambatan diantaranya, tenaga kerja, peralatan kerja, material, informasi dan komunikasi, karakteristik lokasi proyek, pengelolaan proyek, dan kejadian yang tidak terduga (Ramang et al., 2017).

\section{METODE}

Lokasi yang menjadi objek penelitan adalah pembangunan jalan Provinsi di ruas jalan Parigi dan Sukamanah pada tahun 2019dengan panjang jalan $7 \mathrm{~km}$ dan penelitian inidilakukan pada tahun 2020. Dalam penelitian yang dilakukan menggunakan metode critical chain projectmanajement memiliki tahap-tahap dalam melakukan analisis perencanaan ulang pembangunan jalan Provinsi di ruas jalan Parigi dan Sukamanah adalah:

1. Tahap persiapan, adalah tahap mengkaji permasalahan yang dialami saat proyek yang tidak sesuai target waktu ketika melakukan perencanaan dan pelaksanaan proyek.

2. Tahap pengumpulan data, adalah pengambilan data primer maupun data skunder yang dilakukan dengan cara wawancara kepada konsultan dan kontraktor yang merencanakan dan melaksanakan proyek pembangaunan jalan.

3. Tahap analisis, mencari jalur pekerjaan kritis menggunakan metode critical chain project manajement berdasarkan pemantauan pelaksnaan proyek menggunakan Kurva S, menganalisis alternatif yang dapat digunakan dalam upaya mempercepat waktu proyek dan meminimalisir biaya proyek dengan alternatif penambahan tenaga kerja dan penambahan tenaga kerja pada proyek.

Berdasarkan Keputusan Menteri Tenaga Kerja dan Transmigrasi Republik Indonesia Nomor KEP. 102/MEN/VI/2004 pasal 3, pasal 7, dan pasal 11 ditetapkan bahwa upah penambahan tenaga kerja. Penambahan waktu kerja satu jam pertama, pekerja mendapatkan tambahan upah 1,5 kali upah/jam waktu normal pada penambahan jam kerja berikutnya maka pekerja akan mendapatkan 2 kali upah/jam waktu normal. Penambahan tenaga kerja dimaksudkan untuk menambah produktivitas. Durasi proyek dapat dipercepat dengan penambahan alat berat yang mempunyai produktivitas yang lebih tinggi. Juga perlu diperhatikan luas lahan untuk menyediakan tempat bagi alat berat tersebut danpengaruhnya terhadap produktivitas tenaga kerja (Mandiyo Priyo, 2017). Penelitian ini menggunakan jenis data primer dan sekunder. Data primer adalah data yang diperoleh secara langsung tanpa perantara, data yang diperoleh adalah dengan observasi, wawancara, Rencana Anggaran Biaya(RAB), time schedule (Kurva S) dan data upah tenaga kerja pada objek penelitian proyek. Data sekunder adalah data yang diperoleh dengan cara tidak langsung melainkan melalui sumber lain atau perantara, baik lisan maupun tertulis. Data sekunder yang diperoleh adalah penelitian terdahulu tentang perencanaan proyek.

\section{PEMBAHASAN}

Data Penelitian yang sudah dikumpulkan dapat dilihat pada Tabel 1.

\subsection{Hubungan Antar Kegiatan}

Untuk menentukan jalur pekerjaan kritis diperlukan terlebih dahulu hubungan antar kegiatan yang akan dimaksudkan kedalam Microsoft project 2019. Menghubungkan antar kegiatan dengan cara mengisi kolom 
Tabel 1. Rekapitulasi Data

\begin{tabular}{|c|c|c|c|c|}
\hline Code & Kegiatan & Volume & Hari & Satuan Unit \\
\hline 1 & DIVISI 1. UMUM & & & \\
\hline 1.1 & Mobilisasi & 1.00 & $\begin{array}{c}15 \\
4\end{array}$ & \\
\hline 1.2 & Manajemen dan KeselamatanLalu Lintas & 1.00 & $\begin{array}{c}14 \\
0\end{array}$ & (1.1)SS+14 day \\
\hline 2 & $\begin{array}{l}\text { DIVISI 2. DRAINASE } \\
\text { Pasangan Batu Dengan Mortar }\end{array}$ & & & $(1.2) \mathrm{SS}$ \\
\hline $\begin{array}{l}2.1 \\
2.2\end{array}$ & $\begin{array}{l}\text { Beton K-250 (FC'200) untuk struktur drainase beton } \\
\text { minor }\end{array}$ & $\begin{array}{r}25.00 \\
5.00\end{array}$ & 7 & (2.1)SS \\
\hline 2.3 & $\begin{array}{l}\text { Baja Tulangan Untuk Struktur drainase beton minor } \\
\text { DIVISI 3. PEKERJAANTANAH }\end{array}$ & 375.00 & 7 & (2.2)SS \\
\hline $\begin{array}{c}5 \\
3.1\end{array}$ & Galian Biasa (pelebaran) & $3,407.60$ & 56 & (2.3)FS+7 day \\
\hline 3.2 & Timbunan Biasa dari sumbergalian & 135.00 & 14 & (3.1)FS+49day \\
\hline 3.3 & $\begin{array}{l}\text { Penyiapan Badan Jalan } \\
\text { DIVISI 4. PELEBARAN PERKERASAN DAN } \\
\text { BAHU JALAN }\end{array}$ & $29,853.60$ & 56 & (3.1)SS \\
\hline 4.1 & Lapis Pondasi Agregat Kelas A & $1,119.40$ & 42 & $\begin{array}{l}(4.2) \mathrm{SS}+14 \\
\text { day }\end{array}$ \\
\hline 4.2 & Lapis Pondasi Agregat Kelas B & $1,865.60$ & 42 & (3.3)SS+7 day \\
\hline $\begin{array}{c}4.3 \\
5\end{array}$ & $\begin{array}{l}\text { Lapis Pondasi Agregat Kelas } \mathrm{S} \\
\text { DIVISI 5. PERKERASAN BERBUTIR }\end{array}$ & $2,611.90$ & 42 & (4.1)FS+28 day \\
\hline 5.1 & Lapis Pondasi Agregat Kelas B & 423.40 & 21 & $\begin{array}{l}(4.2) \mathrm{SS}+21 \\
\text { day }\end{array}$ \\
\hline 5.2 & $\begin{array}{l}\text { Perkerasan Beton Semen FSdengan Anyaman Tulangan } \\
\text { Tunggal }\end{array}$ & $7,592.50$ & 91 & (5.1)SS+7 day \\
\hline $\begin{array}{c}5.3 \\
6\end{array}$ & $\begin{array}{l}\text { Lapis pondasi Bawah BetonKurus } \\
\text { DIVISI 6. STRUKTUR }\end{array}$ & $3,188.90$ & 91 & (5.2)SS \\
\hline $\begin{array}{l}\mathbf{0} \\
6.1\end{array}$ & Baja Tulangan U 24 Polos & $110,969.10$ & 98 & (5.1)SS \\
\hline 6.2 & Anyaman Kawat Yang Dilas (Welded Wire Mesh) & $188,070.60$ & 98 & (6.1)SS \\
\hline 6.3 & $\begin{array}{l}\text { Pasangan Batu } \\
\text { DIVISI 7. PENGEMBALIAN KONDISI DAN } \\
\text { PEKERJAANMINOR }\end{array}$ & 680,90 & 49 & (6.2)SS-14 day \\
\hline 7.1 & Lapis Pondasi Agregat A utk Pekerjaan Minor & 50.00 & 42 & $(6.3) \mathrm{FS}+21 d a y$ \\
\hline 7.2 & Lapis Pondasi Agregat B utk Pekerjaan Minor & 675.00 & 42 & (7.1)SS \\
\hline 7.3 & Marka Jalan Termo Plastik & & 28 & (7.1)SS+14day \\
\hline
\end{tabular}

Sumber : Daftar analisis pekerjaan, time schedule, dan laporan bulanan proyek pada pembangunan Jalan Parigi

predecessors (tugas yang harus diselesaikan sebelum tugas tertentu dimulai) sesuai dengan time schedule. Tahap selanjutnya adalah mencari jalur kritis atau critical job path pada proyek tersebut, dimana merupakan aktivitas yang sangat mempengaruhi panjang pendeknya keseluruhan proyek. Jalur pekerjaan kritis didapatkan dari aplikasi Microsoft Project. Jalur pekerjaan kritis dapat diidentifikasi seperti tertera pada Tabel 2.

\subsection{Biaya Upah Tenaga Kerja}

Proyek kontruksi yang dilaksanakan pada ruas jalan yang menghubungkan daerah Parigi dengan daerah Sukamanah memiliki nilai 
Tabel 2. Jalur pekerjaan kritis

\begin{tabular}{clc}
\hline Code & \multicolumn{1}{c}{ Kegiatan } & Durasi hari \\
\hline 3.1 & Galian Biasa (Pelebaran) & 56 \\
3.3 & Penyiapan Badan Jalan & 56 \\
4.2 & Lapis Pondasi Agregat Kelas B & 42 \\
5.1 & Lapis Pondasi Agregat Kelas B & 21 \\
5.2 & Perkerasan Beton Semen FS dengan Anyaman Tulangan & 91 \\
& Tunggal & \\
5.3 & Lapis Pondasi Bawah Beton Kurus & 91 \\
7.1 & Baja Tulangan U 24 Polos & 98 \\
7.2 & Anyaman Kawat Yang Dilas (Welded Wire Mesh) & 98 \\
7.3 & Pasangan Batu & 49 \\
\hline
\end{tabular}

kontrak atau acuan nominal upah/gaji pekerja sebagai berikut:

Contoh perhitungan upah/jam pada pekerja mandor

Pekerja = Mandor

Biaya upah perhari $=\mathrm{Rp} 120,000.00$

Jam kerja perhari $=7 \mathrm{jam} /$ hari

Biaya upah perjam $=$ biaya upah perhari $\div$ jam

kerja perhari $\quad=\operatorname{Rp~} 120,000.00 \div 7 \mathrm{jam}$

$=\mathrm{Rp} \mathrm{17,142.86/ \textrm {jam }}$
Jadi upah pekerja pada mandor sebesar Rp. 17,142.86/jam, pada pekerjaan lain pun sama perhitungannya dan hasil dari perhitungan biaya upah perjam dapat dilihat pada tabel 3 dan 4 .

\subsection{Percepatan Durasi Kerja Menggunakan Metode Crashing}

Metode crashing dapat dilakukan pada proyek yang mengalami keterlambatan waktu atau pada proyek yang ingin dipersingkat waktu

Tabel 3 Acuan Upah Tenaga Kerja

\begin{tabular}{|c|c|c|c|}
\hline No & Pekerjaan & Upah/Hr(Rp) & Upah/Jam(Rp) \\
\hline 1 & Mandor & $120,000.00$ & $17,142.86$ \\
\hline 2 & Kepala Tukang & $110,000.00$ & $15,714.29$ \\
\hline 3 & Tukang Batu & $65,000.00$ & $9,285.71$ \\
\hline 4 & Tukang Kayu & $65,000.00$ & $9,285.71$ \\
\hline 5 & $\begin{array}{l}\text { Tukang } \\
\text { Besi/Baja }\end{array}$ & $65,000.00$ & $9,285.71$ \\
\hline 6 & Tukang Cat & $65,000.00$ & $9,285.71$ \\
\hline 7 & Tukang Listrik & $65,000.00$ & $9,285.71$ \\
\hline 8 & Tukang Pipa & $65,000.00$ & $9,285.71$ \\
\hline 9 & Tukang Plitur & $65,000.00$ & $9,285.71$ \\
\hline 10 & Tukang Taman & $65,000.00$ & $9,285.71$ \\
\hline 11 & Tukang & $65,000.00$ & $9,285.71$ \\
\hline 12 & $\begin{array}{l}\text { Pembantu } \\
\text { Tukang }\end{array}$ & $42,000.00$ & $6,000.00$ \\
\hline 13 & Pekerja Biasa & $42,000.00$ & $6,000.00$ \\
\hline 14 & Operator & $75,000.00$ & $10,714.29$ \\
\hline 15 & Mekanik & $65,000.00$ & $9,285.71$ \\
\hline 16 & PembantuSopir & $42,000.00$ & $6,000.00$ \\
\hline 17 & $\begin{array}{l}\text { Pembantu } \\
\text { Operator }\end{array}$ & $50,000.00$ & $7,142.86$ \\
\hline 18 & $\begin{array}{l}\text { Pembantu } \\
\text { Mekanik }\end{array}$ & $42,000.00$ & $6,000.00$ \\
\hline
\end{tabular}


Tabel 4 Upah Tenaga Kerja

\begin{tabular}{lcccrrr}
\hline \multirow{2}{*}{ Code } & \multirow{2}{*}{ Divisi Pekerjaan } & \multirow{2}{*}{ Satuan } & Jumlah & \multirow{2}{*}{ Upah/Hari (RP) } & Durasi & \multirow{2}{*}{ Upah Pekerja(Rp) } \\
\cline { 3 - 4 } & & & Pekerja & Hari & \\
\hline 1.2 & Divisi 1 & $\mathrm{M}^{3}$ & 6 & $535,000.00$ & 140 & $74,900,000.00$ \\
2.1 & Divisi 2 & $\mathrm{M}^{3}$ & 9 & $640,000.00$ & 7 & $4,480,000.00$ \\
2.2 & Divisi 2 & $\mathrm{M}^{3}$ & 4 & $315,000.00$ & 7 & $2,205,000.00$ \\
2.3 & Divisi 2 & $\mathrm{M}^{3}$ & 4 & $315,000.00$ & 7 & $2,205,000.00$ \\
3.1 & Divisi 3 & $\mathrm{M}^{3}$ & 4 & $325,000.00$ & 56 & $18,200,000.00$ \\
3.2 & Divisi 3 & $\mathrm{M}^{3}$ & 2 & $520,000.00$ & 14 & $2,730,000.00$ \\
3.3 & Divisi 3 & $\mathrm{M}^{2}$ & 3 & $250,000.00$ & 56 & $14,000,000.00$ \\
4.1 & Divisi 4 & $\mathrm{M}^{3}$ & 5 & $380,000.00$ & 42 & $15,960,000.00$ \\
4.2 & Divisi 4 & $\mathrm{M}^{3}$ & 5 & $390,000.00$ & 42 & $16,380,000.00$ \\
4.3 & Divisi 4 & $\mathrm{M}^{3}$ & 4 & $325,000.00$ & 42 & $13,650,000.00$ \\
5.1 & Divisi 5 & $\mathrm{M}^{3}$ & 7 & $520,000.00$ & 21 & $10,920,000.00$ \\
5.2 & Divisi 5 & $\mathrm{M}^{3}$ & 21 & $1,310,000.00$ & 91 & $132,860,000.00$ \\
5.3 & Divisi 5 & $\mathrm{M}^{3}$ & 17 & $1,160,000.00$ & 91 & $105,560,000.00$ \\
6.1 & Divisi 6 & $\mathrm{Kg}^{3}$ & 10 & $705,000.00$ & 98 & $69,090,000.00$ \\
6.2 & Divisi 6 & $\mathrm{Kg}^{3}$ & 5 & $380,000.00$ & 98 & $37,240,000.00$ \\
6.3 & Divisi 6 & $\mathrm{M}^{3}$ & 10 & $705,000.00$ & 49 & $34,545,000.00$ \\
7.1 & Divisi 7 & $\mathrm{M}^{3}$ & 4 & $315,000.00$ & 42 & $13,230,000.00$ \\
7.2 & Divisi 7 & $\mathrm{M}^{3}$ & 4 & $315,000.00$ & 42 & $13,230,000.00$ \\
7.3 & Divisi 7 & $\mathrm{M}^{3}$ & 2 & $130,000.00$ & 28 & $3,640,000.00$ \\
& Total & & 129 & & & $585,025,000.00$ \\
\hline
\end{tabular}

penyelesaiannya (Putra \& Hartati, 2017). Dalam upaya mengoptimalkan waktu proyek alteratif yang dilakukan adalah menambah jam lembur dan menambah tenaga kerja, sebagai alternatif yang dilakukan. Hal ini juga akan berpengaruh terhadap biaya proyek. Contoh perhitungan upah tenaga kerja normal pada divisi 3.1 pekerjaan galian biasa (pelebaran jalan).

Durasi normal hari kerja $=56$ hari

Upah tenaga kerja $=$ jumlah tenaga kerja $\mathrm{x}$ upah perhari

Mandor $\quad=1 \times$ Rp. $120,000.00$

$=\operatorname{Rp~120,000.00~}$

Operator excavator $=1 \times \mathrm{Rp} .75,000.00$

$$
=\text { Rp. } 75,000.00
$$

Mengukur ketebalan jalan= 1 x Rp. $65,000.00$

$$
=\text { Rp. } 65,000.00
$$

Penanganan lalulintas $\quad=1 \mathrm{x} \mathrm{Rp} .65,000.00$

$=$ Rp. $65,000.00$

Total biaya upah

$=$ upah tenaga kerja $\mathrm{x}$

durasi normal

Upah tenaga kerja $=$ Rp. $325,000.00$

$$
\begin{aligned}
& =\text { Rp 325,000.00 x } 56 \text { hari } \\
& =\text { Rp. } 18,200,000.00
\end{aligned}
$$

Jadi pada pekerjaan divisi 3.1 galian biasa (pelebaran jalan) memiliki upah sebesar Rp. $18,200,000.00$ untuk durasi waktu 56 hari kerja. Begitupun perhitungan biaya upah tenaga kerja pada proyek, rekapitulasi hasil dari perhitungan biaya upah tenaga kerja dalam durasi normal. Jadi pada pelaksanaan proyek kontruksi pembangunan jalan membutuhkan biaya sebesar Rp.585,025,000.00 untuk upah pekerja.

\subsection{Penambahan Jam Kerja (lembur)}

Alternatif yang dilakukan oleh konsultan dan kontraktor untuk mengoptimalkan pelaksanaan proyek adalah penambahan jam kerja (lembur), untuk mengatasi keterlambatan waktu. Contoh perhitungan 1 jam lembur pada mandor adalah sebagai berikut :

Mandor $=$ upah normal 1 jam x 1,5

$$
\begin{aligned}
& =\operatorname{Rp} 17,142.86 \times 1,5 \\
& =\mathrm{Rp} 25,714.29
\end{aligned}
$$

Jadi upah penambahan 1 jam lembur pada pekerja mandor adalah $\mathrm{Rp}$ 25,714.29. Perhitungan yang sama dilakukan pada pekerjaan dan tenaga kerja yang lain. Contoh crashing durasi hari kerja penambahan jam lembur pertama pada pekerjaan divisi 3, pekerjaan galian biasa

Produktivitas harian $=\frac{\text { volume }}{\text { durasi normal }}$

(Sulistyo \& Fikri, 2021).

$=\frac{298,536}{56}=5,33 \mathrm{~m}^{3} /$ hari 
Produktivitas $=\frac{\text { produktivitas harian }}{\text { jam kerja normal }}$ $=\frac{5,33}{7}=0,76 \mathrm{~m}^{3} / \mathrm{jam}$

Produktivitas Crashing

$=($ jam normal $x$ produktivitas perjam $)$

$+\left(\begin{array}{c}\text { jumlah jam lembur } x \text { produktivitas pekerja } \\ x \text { predouktivitas perjam }\end{array}\right)$

$$
\begin{aligned}
& =(7 \times 0,76)+(1 \times 0,9 \times 0,76) \\
& =6,02 \mathrm{~m}^{3} / \text { hari }
\end{aligned}
$$

Crash Duration $=\frac{\text { volume }}{\text { produktivitas crashing }}$

$$
=\frac{298,536}{6,02}=49,6=50 \text { hari }
$$

Maksimal crash $=$ durasi normal - crash duration

$$
=56-50=6 \text { hari }
$$

Jadi pada pekerjaan galian biasa (pelebaran jalan) pada divisi 3.1, crash duration didapatkan nilai 50 hari atau dapatdi crash 6 hari durasi kerja. Begitupun pada pekerjaan lain yang berada pada jalur kritis seperti pada tabel 5 .

Dari hasil tabel 5 maka dalam alternatif penambahan 1 jam lembur dapat mengubah durasipelaksanaan proyek menjadi lebih cepat, perencanaan dan pelaksanaan proyek dimulai pada tanggal 5 Juni 2019 dan selesai pada tanggal 30 Oktober 2019 dengan durasi proyek menjadi 148hari, atau pelaksanaan proyek dapat maju selama 6 hari kerja dari durasi awal. Contoh perhitungan crash cost pada jalur kritis, pekerja mandor untuk penambahan lembur $1 \mathrm{jam}$ pertama pada pekerjaan divisi 3.1, pekerjaan galian biasa (pelebaran jalan).

Upah lembur 1 jam pertama $=1,5$ dari upah perhari

Durasi setelah crashing $\quad=50$ hari

Biaya lembur $1 \mathrm{jam}=1,5 \mathrm{x}$ biaya normal perjam

Mandor $=1,5 \times \mathrm{Rp} 17,142.86=\mathrm{Rp} 25,714.29$

Operator excavator $=1,5 \times \mathrm{Rp} 10,714.29$

$$
=\operatorname{Rp} 16,071.43
$$

Mengukur ketebalan jalan $=1,5 \times$ Rp 9,285.71

$$
=\operatorname{Rp} 13,928.57
$$

Penanganan lalulintas $=1,5 \times \mathrm{Rp} 9,285.71$

$$
=\operatorname{Rp} 13,928.57
$$

Biaya lembur perhari $=$ jumlah tenaga kerja $\mathrm{x}$ upah tenaga kerja lembur

1 jam Mandor $=1 \times \operatorname{Rp} 25,714.29$

$$
=\operatorname{Rp} 25,714.29
$$

Operator excavator $=1 \times \mathrm{Rp} 16,071.43$

$$
=\operatorname{Rp} 16,071.43
$$

Mengukur ketebalan jalan $=1 \times \mathrm{Rp} 13,928.57$

$$
=\operatorname{Rp} 13,928.57
$$

Penanganan lalul intas $=1 \times \mathrm{Rp} 13,928.57$

$$
=\operatorname{Rp} 13,928.57
$$

Biaya lembur perhari $=$ Rp. $69,642.80$

Total biaya upah lembur $1 \mathrm{jam} / \mathrm{hari}=$ total upah normal/hari + total upah lembur 1 jam Total biaya upah lembur jam/hari $=\operatorname{Rp} 325,000.00+\operatorname{Rp} 69,642.80$ $=$ Rp. 394,642.80

Tabel 5. Crashing durasi hari kerja

\begin{tabular}{cccccccc}
\hline Code & $\begin{array}{c}\text { Volume } \\
\left(\mathrm{m}^{3}\right)\end{array}$ & $\begin{array}{c}\text { Durasi } \\
\text { (hari) }\end{array}$ & $\begin{array}{c}\text { Produktvitas } \\
\text { Harian }\end{array}$ & $\begin{array}{c}\text { Prduktivitas/ } \\
\text { Jam }\end{array}$ & $\begin{array}{c}\text { Produktivitas } \\
\text { Sesudah } \\
\text { Crashing }\end{array}$ & $\begin{array}{c}\text { Durasi } \\
\text { Crashing } \\
\text { (hari) }\end{array}$ & $\begin{array}{c}\text { Crash } \\
\text { (hari) }\end{array}$ \\
\hline 3.1 & 340.76 & 56 & 6.09 & 0.87 & 6.87 & 49.6 & 6 \\
3.3 & 298.54 & 56 & 5.33 & 0.76 & 6.02 & 49.6 & 6 \\
4.2 & 186.56 & 42 & 4.44 & 0.63 & 5.01 & 37.2 & 5 \\
5.1 & 423.4 & 21 & 20.16 & 2.88 & 22.75 & 18.6 & 2 \\
5.2 & 759.25 & 91 & 8.34 & 1.19 & 9.42 & 80.6 & 10 \\
5.3 & 318.89 & 91 & 3.50 & 0.50 & 3.95 & 80.6 & 10 \\
6.1 & 110.97 & 98 & 1.13 & 0.16 & 1.28 & 86.8 & 11 \\
6.2 & 188.08 & 98 & 1.92 & 0.27 & 2.17 & 86.8 & 11 \\
6.3 & 680.9 & 49 & 13.90 & 1.99 & 15.68 & 43.4 & 6 \\
\hline
\end{tabular}


Tabel 6. Cost crashing pada pekerjaan yang berada di jalur kritis

\begin{tabular}{ccccc}
\hline Code & $\begin{array}{c}\text { Durasi } \\
\text { Normal }\end{array}$ & $\begin{array}{c}\text { Crash } \\
\text { Duration }\end{array}$ & $\begin{array}{c}\text { Biaya upah } \\
\text { Sebelum Crashing } \\
(\mathrm{Rp})\end{array}$ & $\begin{array}{c}\text { Biaya upah } \\
\text { Crashing lembur1 Jam } \\
(\mathrm{Rp})\end{array}$ \\
\hline 3.1 & 56 & 50 & $18,200,000.00$ & $19,732,000.00$ \\
3.3 & 56 & 50 & $14,000,000.00$ & $15,179,000.00$ \\
4.2 & 42 & 37 & $16,380,000.00$ & $17,552,000.00$ \\
5.1 & 21 & 19 & $10,920,000.00$ & $11,997,000.00$ \\
5.2 & 91 & 81 & $132,860,000.00$ & $131,104,000.00$ \\
5.3 & 91 & 81 & $105,560,000.00$ & $114,094,000.00$ \\
6.1 & 98 & 87 & $69,090,000.00$ & $74,478,000.00$ \\
6.2 & 98 & 87 & $37,240,000.00$ & $40,144,000.00$ \\
6.3 & 49 & 43 & $31,360,000.00$ & $36,212,000.00$ \\
\hline
\end{tabular}

Tabel 7. Crashing durasi kerja pada penambahan pekerja

\begin{tabular}{llccccccc}
\hline Code Volume $\left(\mathrm{m}^{3}\right)$ & $\begin{array}{c}\text { Durasi } \\
\text { (hari) }\end{array}$ & $\begin{array}{c}\text { Jumlah } \\
\text { Pekerja } \\
\text { Setelah } \\
\text { ditambah }\end{array}$ & $\begin{array}{c}\text { Prduktivitas } \\
\text { awal/ } \\
\text { Orang/hari }\end{array}$ & $\begin{array}{c}\text { Prduktivitas/ } \\
\text { Orang/hari }\end{array}$ & $\begin{array}{c}\text { Prduktivitas } \\
\text { setelah } \\
\text { ditambah/ } \\
\text { Orang/Hari }\end{array}$ & $\begin{array}{c}\text { Durasi } \\
\text { Crashing } \\
\text { (hari) }\end{array}$ & $\begin{array}{c}\text { Crash } \\
\text { Hari }\end{array}$ \\
\hline 3.3 & 298.536 & 56 & 4 & 5.33 & 1,78 & 7,11 & 42 & 14 \\
4.2 & 186.56 & 42 & 7 & 4.44 & 0,8 & 6,22 & 30 & 12 \\
5.1 & 423.4 & 21 & 9 & 20.16 & 2,88 & 25,92 & 16 & 5 \\
5.2 & 759.25 & 91 & 22 & 8.34 & 0,40 & 8,74 & 87 & 4 \\
5.3 & 318.89 & 91 & 18 & 3.50 & 0,21 & 3,71 & 86 & 5 \\
\hline
\end{tabular}

Dari tabel 6 didapatkan perbandingan biaya sebelum crashing dengan biaya setelah crashing penambahan jam kerja (lembur) dengan hasil biaya sebesar Rp. 606,722,000.00 dengan selisih penambahan biaya sebesar Rp. 21,697,000.00.

\subsection{Penambahan Tenaga Kerja}

Alternatif kedua yang dapat dilakukan oleh kontraktor dan konsultan dalam mengoptimalkan pelaksanaan proyek adalah dengan upaya menambah tenaga kerja berdasarkan hasil dari wawancara yang dilakukan, penambahan tenaga kerja dilakukan pada pekerjaan yang memiliki volume tinggi atau pada pekerjaan yang berada jalur kritis. Contoh perhitungan crashing durasi waktu alternatif penambahan tenaga kerja pada pekerjaan divisi 3.3, penyiapan badan jalan sebagai berikut.

Dari hasil tabel 7 maka dalam alternatif penambahan tenaga kerja dapat mengubah durasi pelaksanaan proyek menjadi lebih cepat, perencanaan dan pelaksanaan proyek dimulai pada tanggal 5 Juni 2019 dan selesai pada tanggal 01 November 2019 dengan durasi proyek menjadi 150 hari, atau pelaksanaan proyek dapat mundur selama 4 hari kerja dari durasi awal. Contoh perhitungan penambahan biaya upah tenaga kerja pada pekerjaan divisi 3.3, pekerjaan penyiapan badan jalan. Jumlah pekerja $=4$ orang, hasil tambahan 1 Durasi hari setelah crashing $=42$ hari

Upah pekerja/hari $=$ Rp. 65,000.00. Total upah penyiapan badan jalan $=$ penambahan biaya upah + upah mandor $=$ Rp.8,190,000.00+ Rp. $5,040,000.00=$ Rp.13,230,000.00

Pada tabel 8 didapatkan perbandingan biaya keadaan awal dengan biaya setelah crashing penambahan tenaga kerja dengan biaya sebesar Rp. 576,750,000.00 dapat menghemat biaya sebesar Rp. 8,275,000.00.

\subsection{Alternatif Yang Digunakan Dalam Perencanaan Proyek}

Metode crashing yang digunakan dalam alternatif penambahan jam kerja (lembur) dan penambahan tenaga kerja terdapat perbedaan biaya yang dihasilkan.

Dari tabel 9 dapat diambil kesimpulan crashing dari kedua alternatif bahwa menggunakan penambahan tenaga kerja menjadi pilihan dan dapat digunakan oleh 
Tabel 8. Biaya upah penambahan tenaga kerja

\begin{tabular}{|c|c|c|c|c|c|}
\hline Code & Pekerjaan & $\begin{array}{c}\text { Biaya } \\
\text { Pekerja/Hari }\end{array}$ & $\begin{array}{l}\text { Jumlah } \\
\text { Pekerja }\end{array}$ & $\begin{array}{c}\text { Durasi } \\
\text { Crashing } \\
\text { (hari) }\end{array}$ & $\begin{array}{c}\text { Cost } \\
\text { Crashing (Rp) }\end{array}$ \\
\hline & Mandor & $120,000.00$ & & & \\
\hline & Operator & $75,000.00$ & & & \\
\hline & Tukang & $65,000.00$ & & & \\
\hline 3.3 & Penyiapan badan jalan & & 4 & 42 & $13,230,000.00$ \\
\hline 4.2 & $\begin{array}{l}\text { Penebaran adukan } \\
\text { semen }\end{array}$ & & 7 & 30 & $15,600,000.00$ \\
\hline 4.2 & Perapihan bahu jalan & & & & \\
\hline 5.1 & Penghampar agregat B & & 9 & 16 & $10,400,000.00$ \\
\hline 5.2 & Pencangkul beton & & 22 & 87 & $132,675,000.00$ \\
\hline 5.3 & Pencangkul beton & & 18 & 86 & $105,350,000.00$ \\
\hline $\begin{array}{l}6.1 \\
6.1\end{array}$ & $\begin{array}{l}\text { Membentuk baja } \\
\text { Pemasangan Baja }\end{array}$ & & 12 & 82 & $68,470,000.00$ \\
\hline 6.2 & Perakitan kawat Las & & 7 & 70 & $35,700,000.00$ \\
\hline 6.3 & $\begin{array}{l}\text { Pengaduk batu \& } \\
\text { semen }\end{array}$ & & & & \\
\hline 6.3 & Pengangkut batu & & 12 & 37 & $30,895,000.00$ \\
\hline 6.3 & Memasang Batu & & & & \\
\hline
\end{tabular}

Tabel 9. Perbandingan hasil dari kedua alternatif

\begin{tabular}{lccc}
\hline Keterangan & $\begin{array}{c}\text { Keadaan Sebelum } \\
\text { Crashing }\end{array}$ & $\begin{array}{c}\text { Crashing } \\
\text { penambahan } \\
\text { 1 Jam kerja (lembur) }\end{array}$ & $\begin{array}{c}\text { Crashing } \\
\text { penambahan } \\
\text { Tenaga kerja }\end{array}$ \\
\hline $\begin{array}{l}\text { Durasi Kerja } \\
\text { Biaya Pekerja }\end{array}$ & $\begin{array}{c}\text { 154 Hari } \\
\text { Rp }\end{array}$ & Rp 606,722,000,00 & Rp 576,750,000.00 \\
Selisih & $585,025,000.00$ & Rp 21,697,000.00 & Rp $(8,275,000.00)$ \\
\hline
\end{tabular}

kontraktor maupun konsultan dengan durasi crashing 150 hari, didapatkan total biaya menjadi Rp. 576,750,000.00 dan pada alternatif penambahan tenaga kerja dapat menghemat biaya proyek sebesar Rp. 8,275,000.00. Hal ini sesuai penelitian (Priyo, Mandiyo dan Aulia, 2016) dan (Elisabeth Riska Anggraeni, 2017) mendapatkan penambahan waktu lembur lebih efisien dibandingkan dengan penambahan tenaga kerja.

\section{KESIMPULAN DAN SARAN}

\subsection{Kesimpulan}

Durasi aktual pelaksanaan proyek mengalami keterlambatan 4 hari dari target perencanaan, yaitu dimulai pada tanggal 5 Juni 2019 dan selesai pada tanggal 5 November 2019 dengan durasi selama 154 hari. Faktor penyebab keterlambatan waktu proyek adalah material yang digunakan mengalami keterlambatan dalam pengiriman akibat akses jalan yang ditempuh mengalami kemacetan dalam perjalanan, dan pada saat pelaksanaan proyek terjadi curah hujan yang cukup tinggi yang mengakibatkan proyek terhenti.

Hasil dari perhitungan alternatif penambahan jam kerja (lembur) didapatkan biaya setelah crashing sebesar Rp. 606,722,000.00 dengan tambahan biayasebesar Rp. 21,697,000.00 dan durasi proyek menjadi lebih cepat menjadi 148 hari atau maju 6 hari dari durasi awal. Sedangkan hasil dari alternatif penambahan tenaga kerja didapatkan biaya setelah crashing penambahan tenaga kerja sebesar Rp. 576,750,000.00 dapat menghemat biaya sebesar Rp. 8,275,000.00 dan durasi proyekmenjadi lebih cepat menjadai 150 hari atau maju 4 hari dari durasi awal. Alternatif penambahan tenaga kerja menjadipilihan dengan hasil durasi crashing 150 hari, dengan biaya tenaga kerja awal sebesar Rp. 585,025,000,00 
menjadi Rp 576,750,000.00 dapat menghemat biayasebesar Rp. 8,275,000.00.

\subsection{Saran}

Dari hasil penelitian yang dilakukan dalam pengaplikasian metode critical chain project management menggunakan aplikasi Microsoft project, konsultan dapat menerapkan metode ini karena hasil dari perencanaan lebih mudah dipahami dan dapat mengetahui pekerjaan yang menjadi fokus utama pada proyek agar tidak mempengaruhi pekerjaan lain, sehingga tidak mengalami keterlambatan waktu proyek.

Dengan menerapkan metode crashing konsultan dapat mengoptimalkan perencanaan waktu proyek dan biaya proyek sampai batas maksimal. Konsultan dapat menambahkan alternatif lain seperti penambahan alat yang digunakan pada proyek, agar durasi pelaksanaan proyek menjadi lebih cepat dan dapat menghindari terjadinya keterlambatan waktu proyek.

Pada penelitian selanjutnya sebaiknya ditambahkan variabel mengenai penambahan jam lembur menjadi 2 jam kerja dan untuk konsultan supaya ada penambahan durasi proyek sebagai safety factor sebagai antisipasi faktor cuaca buruk.

\section{DAFTAR PUSTAKA}

Araszkiewicz, K. (2017). Application of Critical Chain Management in Construction Projects Schedules in a Multi-Project Environment: A Case Study. Procedia Engineering, 182, 33-41. https://doi.org/10.1016/j.proeng.2017.03.1 08

Elisabeth Riska Anggraeni, D. (2017). Analisis Percepatan Proyek Menggunakan Metode Crashing Dengan Penambahan Tenaga Kerja dan Shift Kerja (Studi Kasus : Proyek Pembangunan Hotel Grand Keisha, Yogyakarta). Journal of Engineering Research and Applications, 605.

Giri, F., Ningrum, A., \& Hartono, W. (2017). Penerapan Metode Crashing Dalam Percepatan Durasi Proyek Dengan Alternatif Penambahan Jam Lembur Dan Shift Kerja ( Studi Kasus: Proyek Pembangunan Hotel Grand Keisha , Yogyakarta ). 583-591.
Mandiyo Priyo, S. S. (2017). Studi Optimasi Waktu dan Biaya dengan Metode Time Cost Trade Off pada Proyek Konstruksi : Studi Kasus Proyek Jalan Bugel-GalurPoncosari Cs. Tahap I, Provinsi D.I. Yogyakarta . Semesta Teknika, 20(2), 172186.

Ningrum, F. G. A., Hartono, W., \& Sugiyarto. (2017). Pengertian Metode Crashing Dalam Percepatan Durasi Proyek. EJurnal Matriks Teknik Sipil, 3.

Olivia, P., \& Puspasari, V. H. (2019). Analisa Percepatan Waktu Proyek Menggunakan Metode Crashing (Studi Kasus : Peningkatan Jalan Pelantaran Parenggean - Tumbang Sangai). Jurnal Teoritis Dan Terapan Bidang Keteknikan, $3(1), 41-52$.

Priyo, Mandiyo dan Aulia, M. R. (2016). Aplikasi Metode Time Cost Trade Off Pada Proyek Konstruksi: Studi Kasus Proyek Pembangunan Gedung Indonesia. Semesta Teknika, 18(1), 30-43.

Putra, Y., \& Hartati, S. (2017). Optimalisasi Waktu Dan Biaya Menggunakan Metode Least Cost Analysis Pada Proyek Peningkatan Jalan Lingkar Kota Dumai. Jurnal Saintis, Vol. 17 No(April), 100112.

Ramang, R., Frans, J. H., \& Djahamouw, P. D. K. (2017). Faktor-faktor keterlambatan proyek jalan raya di kota kupang berdasarkan persepsi stakeholder. Jurnal Sipil Statik, VI(1), 103-116.

Setiawan, S., Syahrizal, \& Dewi, R. A. (2017). Penerapan Metode CPM Dan PERT Pada Penjadwalan Proyek Konstruksi.

Sinaga, T., \& Husin, A. E. (2021). Analysis of Time Efficiency with CCPM Method and BIM in Construction Projects Construction of High-Rise Residential Building Basement. Civil Engineering and Architecture, 9(5), 1465-1477. https://doi.org/10.13189/cea.2021.090519

Sulistyo, A. B., \& Fikri, M. Al. (2021). Proyek Konstruksi Menggunakan Metode Time Cost Trade Off ( Studi Kasus: Proyek Pembangunan Jalan Gorda-Bandung ). 4(1), 25-40.

Tegar, M., Aji, J., Sari, S. N., Studi, P., \& Sipil, T. (2020). Analisis Biaya Percepatan Dengan Metode Time Cost Trade Off Di Pasar. 01(01), 63-72. 